\title{
La Revue de Littérature comparée: un lugar de memoria
}

\author{
Daniel-Henri Pageaux • \\ Sorbonne Nouvelle/Paris III \\ Traducción: Silvia Zenarruza de Clément
}

La Revue de littérature comparée (RLC) cumplió 90 años en 2011. Había que tener audacia, hoy mal medida, para lanzar en 1921 una revista trimestral dedicada a una disciplina literaria cuya apelación era fluctuante, un poco misteriosa, apenas reconocida en la universidad francesa donde no existían más que dos cátedras, en Lyon y luego en Estrasburgo, y cada una con un puñado de estudiantes. Trazar la historia de la revista es también evocar los progresos continuos de la literatura comparada en Francia durante un siglo.

Se debe esta valiente iniciativa a dos universitarios: Fernand Baldensperger (1871-1958) y Paul Hazard (1878-1944), el germanista, hombre de las marcas del Este y el Flamenco atraído por Italia y el Sur de Francia. Los dos hombres, y más particularmente Baldensperger, prepararon largamente el lanzamiento de su revista. Ya en 1914 tenían en mente una colección de estudios y de trabajos, la «Bibliothèque de littérature comparée», para establecer y ampliar la audiencia de la revista. Se creó una asociación de sostén: los Amigos de la Revue de Littérature comparée. Redes de colaboradores se constituyeron muy pronto y desde el primer número, la redacción anunció para los años a venir alrededor de treinta artículos.

El primer número (1/1921) se abre con un artículo La literatura comparada: la palabra y la cosa de Baldensperger y que será durante mucho tiempo un texto canónico. El autor no evita tratar los malentendidos, las «interpretaciones falsas». Ironiza sobre los «paralelos», sobre las «analogías» y los «acercamientos». Si recuerda algunos precedentes, el folklore, "comparatista por naturaleza», es para mejor separarse de él, así como toma sus distancias con el Positivismo de Taine y el rigor de sus posiciones. Recordemos que un momento de decisión, de desacuerdos, había sido el Congreso de Historia Comparada de las Literaturas, realizado en Paris, en 1900, bajo la presidencia de Ferdinand Brunetière. Dos posiciones se enfrentaban: por un lado, la de Gaston Paris, juzgado demasiado cercano al folklore y a la mitología comparada, que pretendía «reducir a elementos simples los diferentes

\footnotetext{
- Catedrático emérito de la Sorbona/Paris III en la que estuvo desde 1975 hasta 2007. Ha dedicado su docencia a estudios de literatura comparada en torno a cuestiones de interculturalidad (viajes, imágenes) y de poética comparada (literatura de mediación, poética de la novela). Ha publicado una treintena de volúmenes (ensayos, manuales, estudios y ediciones críticas). Es co-director de la Revue de Littérature comparée, miembro correspondiente de la Academia de las ciencias de Lisboa y doctor honoris causa de la Universidad de Enna/Sicilia. Últimas publicaciones: Itinéraires comparatistes (J. Maisonneuve éd. 2016) 2 vol., Lectures indiaocéanes. Essais sur les francophonies de I'Océan indien (J. Maisonneuve, 2016) y Azorín (1873-1967) Sur les chemins de l'écriture (I'Harmattan, 2017).
} 
temas sobre los cuales viven las literaturas " y, por otro lado, la posición defendida por el danés Georg Brandes y Brunetière que predicaban el estudio de las «grandes corrientes que atraviesan los diversos grupos nacionales».

Es hacia esta segunda tendencia que se inclina Baldensperger con algunos matices que serán decisivos para el futuro de la disciplina. Existen, en efecto, a su parecer, junto a los grandes nombres y las obras maestras, textos secundarios pero representativos del estado real de la producción literaria y de los gustos de los diversos públicos. Por ejemplo Destouches, más preferido por los alemanes que Molière...Detendríamos allí los ejemplos que permiten un real conocimiento y comprensión del "hecho» literario por el cual Baldensperger había alegado, no sin talento, en su obra: La littérature. Création, succès, durée [La literatura. Creación, éxito, duración] (Flammarion, 1913, reed. 1919).

No es menos cierto que se ve perfilar en ese artículo-manifiesto ciertas elecciones, pero también excesos, que se van a asociar muy rápido a la joven disciplina, más atenta como lo dice su autor, a las «articulaciones» que a los éxitos, a los «istmos y estrechos» que a los «océanos y continentes». Es que hay una «percepción más aguda de la movilidad del mundo», del estudio de las obras "en su devenir» y no del «Panteón de las reputaciones admitidas». No se puede no ser sensible al ideal anunciado: «un nuevo humanismo» para "proveer a la humanidad dislocada de un fondo menos precario de valores comunes.»

La $R L C$ en sus comienzos va mantener un notable equilibrio entre, por una parte, contribuciones eruditas, "artículos de fondo», «notas y documentos» (la rúbrica existe todavía hoy) para cuestiones más precisas, puntuales y, por otro lado, informaciones breves, crónicas, rúbricas tales como "Trabajos en curso" o "Los vivos y los muertos», o «La literatura comparada en acción», que dan testimonio de una voluntad de apertura a la comunidad internacional, tanto universitaria como no. Se encontrarán ecos de la SDN/Sociedad de las Naciones (1930:787), de asociaciones internacionales, informaciones sobre el $70^{\circ}$ aniversario de Freud (1926:525), sobre el tricentenario de Góngora, tan importante para la generación poética del 27 en España (1927:563), sobre las Décadas de Pontigny, encuentros de intelectuales capitales durante la entre-guerra, bajo la dirección de Paul Desjardins (1923: 657). Paralelamente, la «Biblioteca» de la revista conoce un impulso espectacular: de 23 volúmenes publicados en 1925 alcanza los 60 en 1929 y supera el centenar en 1934. Acoge a investigadores de todos los horizontes, especialmente de América del Norte y de la Europa central.

Frente a las contribuciones, sólidas y múltiples que ilustran el «Norte», las de los anglicistas Louis Cazamian, Floris Delattre, Louis Lemonnier, de los germanistas E. Tonnelat y Henri Tronchon, entre otras, se ve, gracias a la acción de Paul Hazard, el avance del «Sur». Éste da el ejemplo con La invasión de las literaturas del Norte en la Italia del siglo XVIII (1921: 30), Los orígenes del Romanticismo en Brasil (1927:111), Los románticos franceses en Méjico (1930: 151). Suscita brillantes colaboraciones, como la del gran arabista español Miguel Asín Palacios, para un conjunto de cuatro artículos (en 1924) sobre la influencia musulmana en la Divina Comedia, de hispanistas franceses entre los cuales algunos serán preciosos colaboradores: el gran Alfred Morel Fatio, J.-J. A. Bertrand, hispanista y germanista, 
Georges Le Gentil, hispanista y lusitanista, Henri Mérimée, Jean Sarrailh y sobre todo Marcel Bataillon, e italianistas, como Herni Hauvette.

Un colaborador de la primera hora fue Paul Van Tieghem (1871-1949), profesor en diversos liceos parisinos y encargado de cursos en la Sorbonne, quien publica en 1931 el primer verdadero manual de literatura comparada en A. Colin. La obra detalla los diversos campos de estudio de la disciplina, poniendo el acento en las influencias, las relaciones internacionales y los lazos de hecho entre literaturas. Un lugar se asigna a una «historia literaria general» que se dedica al estudio de las grandes corrientes de las que Van Tieghem es por así decirlo el especialista, en particular para el Pre-romanticismo y el Romanticismo. 1931 es también el año en que Baldensperger ve sus esfuerzos y su enseñanza reconocidos, con la creación en la Sorbonne de un «Instituto de Literaturas Modernas Comparadas».

Durante la segunda década, aparecen números «especiales»: el primero en 1932 está dedicado a Goethe. Seguirá en 1934 un número sobre Europa central. ¿De qué se va a tratar? De los intercambios entre Europa central y occidental: Los primeros elementos occidentales en la literatura rumana, Las influencias italianas en la literatura croata, Cervantes en la literatura yugoslava, El pensamiento europeo de los siglos XVI y XVII y la literatura eslovena, La parte de lo extranjero en el repertorio del Teatro nacional de Zagreb. Figuras de intermediarios son estudiadas y Paul Hazard elige evocar La influencia de Atenas en 1786. Éste último organizará el número especial sobre España en 1936 para el que da un artículo de síntesis Lo que las letras francesas deben a España, luego uno sobre Portugal en 1938. Sin embargo, no hay que esperar descubrir en ellos ecos de la actualidad. Es por eso que el lector de hoy (como el de antaño) se queda algo insatisfecho. En 1939 saldrá un número dedicado a Racine en el que aparece la firma de un tal Étiemble para una contribución sobre Racine en Méjico. Había hecho una primera aparición con un artículo sobre el Soneto de las vocales de Rimbaud (1939: 235), preludio a inmensos desarrollos.

Baldensperger se retira de la dirección en 1935. Seguirá estando presente, por supuesto, y continuará multiplicando artículos e informes. Su alumno y discípulo Jean-Marie Carré (1887-1958), profesor en Lyon, lo remplaza en la revista, después de haberlo sucedido en la Sorbonne. Defiende en 1920 en Estrasburgo su tesis de doctorado titulada Goethe en Inglaterra, Estudio literario comparado. Afirma que hay "en la base de la literatura comparada» un estudio de "psicología colectiva» y de "psicología individual» que se relaciona en este caso con «la opinión británica en el siglo XIX» y ciertos «individuos de genio». Es también el autor de varias biografías, dos sobre Rimbaud, que lo llevan constantemente a su provincia natal. Seguirá sin embargo las huellas de su maestro yendo a enseñar a los Estados Unidos y, más tarde, al Cairo. Aprovecha esa estadía para publicar Voyageurs et écrivains français en Égypte (1933), un trabajo que orienta la literatura comparada, de manera decisiva, hacia nuevos campos de estudio reagrupados en un tríptico célebre "viajes, imágenes, espejismos».

Jean-Marie Carré siempre ha sido un observador atento de las relaciones entre Francia y Alemania. Sigue de muy cerca la evolución de Europa. En el primer número de 1939 se enorgullece de presentar un colaborador ocasional y prestigioso, Georges Duhamel, que da sus Reflexiones sobre Europa. Al año siguiente, en el número que será el único de 1940, mientras que está «en el ejército», quiere honrar a Paul Hazard, el maestro y el colega, que acaba de ser elegido en la Academia Francesa. Carré recuerda los antiguos lazos, diferentes de los más recientes que se 
han establecido a partir de la dirección de la revista: las reuniones «ardientes» de los "Compañeros», una asociación que prepara una "Universidad nueva». Junto a Duhamel serán defensores esclarecidos de la Escuela y patriotas convencidos.

La $R L C$ deja de aparecer durante los cinco años de guerra: Carré ha elegido el silencio. Se explica sobre eso en el primer número de 1946, en un editorial de título simbólico Recomienzo. Ese número es también un homenaje a Paul Hazard, muerto en 1944. Retengamos el texto dado por Marcel Bataillon, hispanista quien acababa de suceder a Paul Hazard en el Collège de France y se convertirá, al lado de Carré, en co-director de la revista.

Nada se transparenta durante la primera década de la controversia entre «escuela americana» y «escuela francesa». Notemos sin embargo el informe de Que sais-je? de Marius-François Guyard, elaborado por un discípulo de Carré, Jacques Voisine (RLC 1952: 287-288), que pone en el tapete posibles malentendidos. En términos medios, Voisine no puede dejar de notar que teniendo en cuenta «los resultados obtenidos por la escuela francesa», Guyard está obligado a "falsear ligeramente, por exceso de escrúpulos, los resultados de su balance»: «Importantes contribuciones extranjeras $[\ldots]$ corren así el riesgo de ser silenciadas». Se dirá que era difícil abrir en demasía las puertas de un pequeño edificio de 128 páginas, so pena de caer en una magra bibliografía. Pero es el espíritu mismo del comparatismo, al enunciar sus principios y sus criterios de trabajo, el que podía prestarse a críticas.

En ese mismo año 1952, la $R L C$ prefiere festejar sus veinticinco ańos de existencia como lo hace el "gran periódico americano» Books abroad «que ha querido asociarse a ella en un pensamiento común de esperanza y de buena voluntad», para retomar las palabras del editorial firmado por los dos directores, Carré y Bataillon. Siguen largos «mensajes» de amistad: Ernest Erich Noth por Books abroad, Helen Harvitt por la French Review, F. C. Green por les French Studies, Carlo Pellegrini por la Rivista di letterature moderne, Gustave Charlier de la Academia real de Bélgica y finalmente Hans Pyritz por Euphorion.

La $R L C$ está ahora editada por la casa Didier. Continuando la «Biblioteca», los «Estudios de literatura extranjera y comparada» tienen en su activo en 1956 una amplia veintena de volúmenes. La secretaría está confiada a Basil Munteano, de origen rumano e investigador en el CNRS ${ }^{1}$. Él será un trabajador infatigable y exigente. Pero sabe hacer compartir sus entusiasmos, como para la obra de JeanMarie Carré, Les écrivains français et le mirage allemand [Los escritores franceses y el espejismo alemán] (1947) (RLC 1948: 146-154) o para rendir homenaje a Ernst Robert Curtius (1951: 283). Se lo reencuentra en 1953, en ocasión de un debate sobre la disciplina organizado por la $R L C$ en el que intervienen Franco Simone por Italia, Harry Levin para dar «un punto de vista del otro lado del Atlántico», Walter Höller por Alemania y Henri Roddier por Francia. La «conclusión provisoria» es anónima, pero mucho más tarde el texto figura en la muy original y valiente suma que Munteano da bajo el título Constantes dialectiques en littérature et histoire. Problèmes, recherches, perspectives [Constantes dialécticas en literatura e historia. Problemas, investigaciones, perspectivas] (Didier, 1967: 76-83).

Franco Simone emite numerosas reservas frente a las críticas que Benedetto Croce dirige a la literatura comparada y, más aún, las de Arturo Farinelli quien, de pronto, se muestra reservado exagerando los valores individuales de la obra literaria. Harry Levin, tirando algunos dardos a los defensores de la escuela francesa, tildados de «aduaneros», resume en una brillante propuesta lo esencial 
del debate: «El método formalista no es para nada incompatible con el método histórico». Cerca de veinte años más tarde, después de otros diálogos de sordos, Itamar Even Zohar, con su «teoría» del polisistema, no dirá otra cosa. W. Höllerer elabora un estado presente detallado de los estudios comparatistas en Alemania, subrayando que la tendencia es «interrogar la obra misma, tomada en sí y en sus relaciones con la literatura occidental». Henri Roddier, alegando por «la historia de las ideas», defiende también un punto de vista histórico que matiza con un correctivo "geográfico» que da cuenta de los espacios considerados. La «conclusión provisoria», siguiendo de cerca el artículo de Baldensperger de 1921, no puede sino constatar la emergencia de una «nueva literatura comparada... en oposición casi radical con nuestras laboriosas construcciones». Si «lo anónimo» se rehusaba a elegir, había por lo menos formulado un diagnóstico útil.

La $R L C$, en la persona de Marcel Bataillon (Jean-Marie Carré está cada vez más enfermo), se va a comprometer en la constitución de una Sociedad Francesa de Literatura Comparada/SFLC cuyo primer congreso tendrá lugar en Burdeos en marzo de 1956. Se encontrará fácilmente en las columnas de la revista, de 1954 a 1956, los trabajos preparatorios de la comisión constituyente cuyo secretario es Robert Escarpit, anglicista pasado al comparatismo y organizador más tarde, en 1970, del congreso internacional de la AILC/ICLA en Burdeos.

En 1958 desaparecen, con algunos meses de intervalo, Baldensperger y Carré. Bataillon redacta dos admirables retratos intelectuales. Si continúa manteniendo una distancia respetuosa con el primero al que no duda en llamar con admiración «un gran tipo», es fácil ver que con Carré a la admiración se agrega la simpatía: «Trabajar con él en la Revue era recibir constantes lecciones de buena gracia y de perseverancia en la labor». Se convierte en 1958 en director de la revista hasta su muerte en 1977. Pero a partir de 1973 llama a Jacques Voisine para secundarlo y como para perpetuar la tradición de la co-direccción.

A fines de los años 1950, la autoridad y la influencia de Marcel Bataillon (1895-1977) han adquirido desde hace tiempo una dimensión internacional. Nada predisponía, al principio, a este joven helenista al hispanismo. Pero una estadía de estudios en España desde el fin de 1915 hasta junio de 1916 es para él una revelación. Habiendo obtenido el primer puesto en el concurso de agregación de español en 1920, vuelve a Madrid, a la Casa de Velázquez y entrega poco tiempo después un tema de tesis ambicioso: "Erasmo en España». Encargado de cursos en Argel defiende su tesis monumental en 1937. Elegido en la Sorbonne, pronto se convierte en director del Instituto Hispánico. En 1941 es detenido y encarcelado por un tiempo. Cuando termina la guerra, es elegido en el Collège de France para suceder a Paul Hazard y pronto comenzará a administrar ese establecimiento durante largos años. Es allí que recibía, cada año, a los miembros de la SFLC que él había contribuido a fundar y de la cual fue durante mucho tiempo presidente.

La $R L C$ va a atravesar el año 1968 sin cambiar en nada su ideal de variedad, de diversidad. Al año siguiente (1969: 566-570) se publica el informe del coloquio de la SFLC que se realizó en Saint-Cloud, remplazando el congreso anual. El tema elegido, "Imagen y Literatura», muestra una orientación más "generalista» que «comparatista». André-Michel Rousseau, profesor en Aix en Provence, y autor con Claude Pichois del célebre manual La littérature comparée (Colin, 1967), ha sabido dar cuenta en un tono justo y preciso de este «encuentro» donde se debatió, entre otros, las relaciones complejas entre cine y literatura. Como para no estar 
al margen de ese debate de ideas, la $R L C$ (1969: 570) anuncia que se propone dedicar «una parte de algunos fascículos al estudio de una cuestión», comenzando por «la metodología de la literatura comparada» y «el género de la novela corta, particularmente en la época moderna o contemporánea». El anuncio es publicado nuevamente (1970: 142) y está junto al de A.-M. Rousseau: el lanzamiento de un Bulletin de liaison [Boletín de comunicación] de la SFLC convertida en SFLGC (Société Française de Littérature Générale et Comparée). Otra iniciativa: como la revista no publicaba más desde 1962 su «Bibliografía», la redacción decide crear en 1971 una rúbrica «Revista de revistas» que durará hasta los últimos años del siglo. Último cambio y no el menor: la muerte de Basil Munteano en 1972 al que Bataillon rinde un homenaje emotivo (1972: 321-332) provoca una reorganización de la secretaría, atendida de ahora en más por Jacques Body, profesor en la Universidad de Tours. Los "Estudios de literatura extranjera y comparada" publicarán en 1975 su tesis sobre "Girardoux y Alemania»: es el $74^{\circ}$ volumen de la colección. Finalmente, la llegada a la co-dirección de la revista de Jacques Voisine (1914-2000), anglicista, con una tesis sobre Jean-Jacques Rousseau en Inglaterra en la época romántica (1956), profesor en la Sorbonne Nouvelle/Paris III, parece marcar una nueva época.

Una evolución se produce aún en 1974. La revista cambia su cobertura y adopta un grafismo modernista. Mejor aún: un doble número (3-4/1974) hace entrar «Las literaturas francófonas y anglófonas del África negra» en el campo de las preocupaciones comparatistas. Se remarcan, entre otras contribuciones, la de Maryse Condé sobre Negritud cesariana y negritud senghoriana, cuando acababa de defender en la Sorbonne Nouvelle su tesis de doctorado dirigida por Étiemble. Vendran luego un número especial sobre Milton (2/1975), los Mélanges ${ }^{2}$ en memoria de Jean Bourrily, presentados por Jean Fabre, dedicados a Polonia, Francia e Inglaterra (1-2/1976), Problemáticas de la novela corta (4/1976). Se dará un lugar aparte al número triple (2-3-4/1978) a la memoria de Marcel Bataillon, organizado en tres secciones: renacimiento, América latina, Varia. Jacques Voisine, en un prefacio muy denso, hace de Bataillon "un comparatista humanista».

Un nuevo período de una quincena de años se abre para la $R L C$. Los números Varia, bajo el título Investigaciones comparatistas del Renacimiento a nuestros días, alternan bastante regularmente con los números especiales preparados por un responsable, a veces exterior a la Revista, en relación con el Comité de redacción. Nos limitaremos a dar algunos ejemplos: Eslavos y Occidentales. Encuentros (2/1979), Faulkner (3/1979), Literatura y nación en el siglo XX (4/1980), Dostoïevski europeo (3-4/1981), Manierismos (3/1982), Henry James (3/1983), Checos y Eslovacos entre el Este y el Oeste (4/1983), Gaston Bachelard para el centenario de su nacimiento (2/1984), ¿Autonomía de las minorías culturales? (2/1985) bajo la responsabilidad de Jean-Pierre Morel, convertido en secretario de la revista, Literatura y música confiado a Francis Claudon (3/1987), En recuerdo de Marcel Bataillon por el décimo aniversario de su muerte (4/1987), Literaturas escandinavas confiado a Régis Boyer (2/1988), El Tasso y Europa (4/1988), El texto extranjero (2/1989), América latina y comparatismo literario confiado a D.-H- Pageaux (1/1992) para conmemorar el $4^{\circ}$ centenario del descubrimiento del «Nuevo mundo»...

Jacques Voisine siente la necesidad de hacer un balance en junio 1985 y de comunicar algunas conclusiones sobre el futuro de la revista y de la disciplina formuladas por un grupo de reflexión reunido en la Universidad de Tours 
(1/1984:5-10). Señalar también que a partir de 1980, una «Nota del director» anunciaba la intención de dedicar algunos artículos a cuestiones precisas (2/1980). Una contribución del italiano Franco Meregalli sobre la recepción es publicada, pero la iniciativa no tendrá continuación. En 1995, Jacques Voisine se retira de la dirección, aunque permaneciendo en el comité de redacción, para ceder el puesto a Pierre Brunel (1939), Profesor en la Sorbonne Paris IV y autor de una suma considerable de trabajos sobre Claudel, Rimbaud, la poesía moderna y contemporánea, las relaciones entre mito y literatura, para sólo nombrar los más conocidos.

Pierre Brunel va a dar a la revista, durante cinco años, un nuevo dinamismo. 1996 es el año de cinco números, con, además de entregas sobre Biblia y literatura y Avatares de la épica, un número sobre La Fontaine y la fábula, en ocasión del tricentenario de la muerte del fabulista, organizado por Pierre Brunel y Patrick Dandrey. En 1997 los números especiales se suceden: Francofonía y crítica poscolonial (1/1997) coordinado por Jean-Marc Moura, Escribir después de los totalitarismos por Emmanuel Bouju (2/1997), Ernst Jünger por Julien Hervier (4/1997). En 1998, Pierre Brunel coordina un número sobre Mallarmé y abre los números Varia a conferencias (Claudio Guillen, D.-H. Pageaux) organizadas en la Sorbonne, en el marco del Colegio Internacional de Literatura Comparada que él ha fundado unos años antes. El último número de 1998, sobrepasando las 128 páginas habituales, está centrado sobre los hermanos Heinrich y Thomas Mann «europeos», confiado a Yves Chevrel y Manfred Schmelling. Finalmente, en 1999, Jean-Louis Backès organiza un número titulado Traducir a Racine, mientras que Pierre Brunel publica lo esencial de las actas de un coloquio en torno al mito de Orfeo, abierto por Jacqueline de Romilly de la Academia Francesa (4/1999). Agreguemos, en 2000 el coloquio dedicado a Releer los comparatistas franceses (3/2000).

En el primer número del año 2000, mientras que la revista cambia de presentación y de tipografía y que será difundida por «Les Belles Lettres», Pierre Brunel anuncia que quiere interrumpir «cinco años de gestión solitaria» y que desea volver a la tradición de una «dirección doble». Es por eso que llama a Daniel-Henri Pageaux (1939), profesor en la Sorbonne Nouvelle/Paris III, cuyos dominios (literaturas ibéricas e iberoamericanas, francofonía, pero también las "imágenes» caras a Jean-Marie Carré) son "complementarios de los suyos» y que ha estado asociado a los trabajos de la revista "desde hace mucho tiempo».

¿Es necesario precisarlo? En 1961 Pierre Brunel insistía con razón sobre la continuidad en la gestión de la revista. Podría retomar las palabras que él utilizaba en 1995: «la fidelidad que debemos a nuestros lectores» y la "prudencia», aún «cuando el movimiento de la historia [...] impone innovaciones». Precisemos mejor entonces: más vale suscitar las innovaciones y decidir los cambios que padecerlos.

Desde 2000 un ritmo más controlado se ha impuesto entre los números Varia y los números especiales (dos por año). Otra alternancia ha sido respetada, en la medida en que se pueda, entre obras, literaturas y figuras a las que se rinde homenaje así como con los espacios culturales, transformados a partir de este número en un campo de estudios e investigaciones. En el ańo 2001 se ofrecen tres números especiales, ya que uno se dedica a un ejercicio comparatista controvertido, el $\mathrm{Pa}$ ralelo (2/2001), abordado en una jornada, al que se agregan Pensar y representar el Extremo Oriente (1/2001) y Bélgica como espacio comparatista (3/2001). En 2002 aparecen Un espacio comparatista: el Caribe (2/2002) y La invención de la novela para la juventud en el siglo XIX (4/2002). Pero un acontecimiento imprevisto y 
dramático como es la muerte en un intervalo de pocas semanas, de Jacques Voisine y de Étiembre lleva a elaborar apresuradamente un número de homenajes y de testimonios $(1 / 2002)$.

En 2003, una jornada de trabajo organizada por Jean-Louis Backès bajo el título Poéticas comparatistas dio la materia al número 4, mientras que Danielle Chauvin coordinaba un número sobre Francia y Polonia: ecos y encuentros (2/2003). Para 2004, Brecht entre teatro y teoría realizado por Jean-Pierre Morel (2/2004) y Travesías atlánticas bajo la responsabilidad de Jean Bessière (4/2004). En 2005 África al margen presentado por J.-M. Moura y J. Riesz (2/2005) y, para celebrar el año del Brasil, un número dedicado a las letras brasileras, bajo la responsabilidad de la entrańable Tania Franco Carvalhal, entonces Presidente de la AILC (4/2005). Señalemos una innovación, con la entrada en la escena comparatista de las literaturas «indoceánicas» (2/2006) y un Homenaje a Borges (4/2006). En 2007 es un homenaje al académico François Cheng que forma parte del Comité de honor de la revista (2/2007). En 2008, aparecen Autobiografias (1/2008) y La literatura y los escritores de Túnez (3/2008). Para 2009, Literatura y politica (1/2009) y Homenaje a Gogol (3/2009) presentado por Claude De Grève, fiel colaboradora. Para 2010, Bernard Franco (Paris IV) es el responsable de un número titulado Arabia feliz $(1 / 2010)$, mientras que en el número 4 se publicaban las actas de un homenaje a Charles Dédéyan, una de las figuras principales del comparatismo francés, para el centenario de su nacimiento. El año 2011 se abrió con un estado presente del "Comparatismo en China», coordinado por la Sra. Meng Zhang (Paris III) que presentó el número al Congreso de Literatura Comparada de Shanghai.

En 2012 Véronique Gély, Profesora en Paris IV, que cubría desde hacía mucho tiempo con competencia y dedicación una secretaría cada vez más pesada, vino a unirse a los dos directores. Es a ella que se debe un número temático sobre Intersecciones de la Antigüedad: los clásicos griegos y latinos y la literatura mundial (4/2012). En 2013 Pierre Brunel ha dirigido un importante número sobre Las grandes figuras extranjeras del comparatismo (2/2013) agrupando los nombres de Georg Brandes, Viktor Zirmunski, Mario Praz, Joseph Campbell, Qian Zhongshu, Henry Remak, Ulrich Weisstein, George Steiner y Edward Saïd. Por su lado, D.-H- Pageaux ha coordinado dos números sobre los Comparatistas a través del mundo (4/2014 y 2/2017) respectivamente dedicados a la «vieja «Europa» (Inglaterra, Países Bajos, Alemania, Portugal, Espańa, Italia, Suiza y Eslovenia) y a una primera apertura al mundo (Japón, Corea del Sur, China, Thailandia, Hungría, Turquía, Egipto y Costa de Marfil). Se mencionarán también otras iniciativas que implican un deseo de innovación y de renovación: Metamorfosis de los mitos (2/2014), Las literaturas del Norte de Europa (2/2015), Problemas de historia literaria india (4/2015) y La Biblia y las literaturas poscoloniales (4/2016).

Nos guardaremos bien de concluir sin dejar de enfatizar sobre la voluntad de apertura de la $R L C$ : apertura a cuestiones muy actuales e internacionales o mejor interculturales, pero apertura también a todos los espacios donde emerge y se afirma, en su diversidad, la disciplina que se llama Literatura General y Comparada. 


\section{Notas}

${ }^{1}$ Centro nacional de la investigación científica, por sus siglas en francés. (N.d.T)

${ }^{2}$ Mélanges [Título de una obra compuesta por artículos reunidos y dedicados a un maestro por sus amigos, sus colaboradores, sus discípulos, en homenaje a ese maestro y tratando de la disciplina en la que se ha distinguido] v.gr. Mélanges offerts à M...., et p. abrév., Mélanges + nom propre: Mélanges Cohen, Mélanges Imbs, etc. Voir l'article de Baldensperger dans les Mélanges Lanson, chez Hachette (BARRès, Cahiers, t.14, 1923, p. 223). http://www.cnrtl.fr/definition/mélanges Centre National de Ressources Textuelles et Lexicales.

\section{Pageaux, Daniel-Henri}

